\section{Amino acid transport}

A Review of Amino Acid Transport Processes in Animal Cells and Tissues. By J. Lerner. Pp. 234. (University of Maine at Orono Press: Orono, Maine, 1978.)

AmINo AcIDS are chemically stable and easy to assay. With rapidly expanding techniques of microperfusion, micropuncture and cell fractionation one might have been forgiven for thinking that most of what was worth knowing about these substances would soon be discovered. This has clearly turned out not to be the case for, despite a torrent of data produced in the past two decades, relatively little is known about the fundamental aspect of transport into and out of cells. The literature is massive, with up to 100 original articles and some half-dozen reviews appearing annually. Professor Lerner is to be congratulated therefore on tackling the mammoth task of reviewing this field and providing a valuable synopsis of current information and concepts.

$\mathrm{He}$ accomplishes his task in 177 pages of readable text which cites just over 900 references up to 1976. The index is excellent and the 15 chapters (some of which are a single page in length) are well laid out. Most data described have been derived from marine invertebrates, insects, parasites and mammals (with detailed considerations of transport in the gut, central nervous system and to a lesser extent the kidney), with the intact organism and isolated preparations considered in detail. There is adequate reference to other tissues and isolated cultured cells, with the differing specificity of particular transport systems according to organ and species suitably highlighted.

Perhaps more than anything else, the complex interactions of the amino acids themselves on their own transport and the paucity of synthetic non-competitive specific inhibitors, have hindered the elucidation of mechanistic details. However, of the effects known, those of hormones, mercury, nucleotides, amino acid analogues, vitamins and sugars are suitably described. The important influence of sodium ion concentration is tackled in detail, although rather surprisingly without reference to the elegant work by Ullrich and his collaborators on the isolated rat renal tubule.

Within the context of the whole organism there are interesting observations on the adaptation and regulation of transport and how transport changes during foetal development. Contributions from the clinical front include the inborn errors of metabolism, dietary deficiencies, malabsorption and starvation.

This volume is comprehensive but strictly a review. The theme is usually clear, but on occasions the book would benefit from an overall synthesis and some comment. Sometimes the argument becomes diffuse, points of interest or inconsistency are not highlighted, and there is little speculative comment. It is disappointing (but also indicative of our knowledge) that proposed mechanisms of transport only occupy 10 pages and there is no mention of any possible role for transmembrane peptides which are known to be important in other transport systems. However, despite these observations the work will undoubtedly be of considerable use to research workers in and students of biochemistry, neurochemistry, comparative physiology, nutrition, regulation biology and I think especially clinical science. It should find a place in all laboratories working on amino acid metabolism.

C. W. J. Owens

C. W. J. Owens is Lecturer in Chemical Science at University College Hospital Medical School, London, UK.

\section{Upper atmosphere, ionosphere and magnetosphere}

Handbook of Astronomy, Astrophysics and Geophysics. Vol. 1: The Earth. 1. The Upper Atmosphere, Ionosphere and Magnetosphere. Edited by C. W. Gordon, V. Canuto and W. I. Axford. Pp. 412. (Gordon and Breach: London, 1978.) $£ 35$.

As this particular volume represents the first of forthcoming volumes on a very wide range of astronomy, astrophysics and geophysics, a few general comments may be in order on the general editorial matter. First, it is not clear whether or not this particular volume (volume 1) is supposed to cover the entire subjects of "The Upper Atmosphere, Ionosphere and Magnetosphere." If other volumes are planned for the above subjects, it should have been mentioned in an editorial note. How many volumes are planned? Is general subject matter for each volume decided? Or is this going to be a collection of review papers as they come along?

Secondly, the volume consists of six articles, a mixture of comprehensive articles covering a very wide range of topics and those covering rather specific topics. Thus, the general editorial policy for the general planning of this handbook is not very clear. Further, there does not seem to be a uniform format: some have an abstract, some do not. Some articles have one page for the title and some do not. For an extensive article, it would be helpful to have at least a Table of Contents on the cover page. Also, if it is going to be truly a Handbook it should have at least a subject index.

Among the articles in the first volume "Hydrogen in the Upper Atmosphere" by B. A. Tinsley, "Auroral Particle Precipitation . . . Observations" by B. A. Whalen and I. B. McDiarmid, and "The Physical Mechanisms of the Inner Van Allen Belt" by M. Walt and T. A. Farley are perhaps the most comprehensive and up-to-date ones in each subject area. The coverage of the article "The Equatorial Electrojet" by D. M. Cunnold is rather limited, and there is little mention of some of the recent developments, such as the relationship between the $F$ region of the ionosphere and the equatorial electrojet. The article "Polar-Cap Absorption Obsevrations and Theory" by G. C. Reid does not cover observations of solar protons in interplanetary space and in the magnetosphere. The coverage of J. R. McAfee's article "Electron Plasma Resonances in the Topside Ionosphere" is reasonable for this limited subject.

Syun-Ichi Akasofu

Syun-Ichi Akasofu is Professor of Geophysics at the Geophysical Institute, University of Alaska, Fairbanks, Alaska.

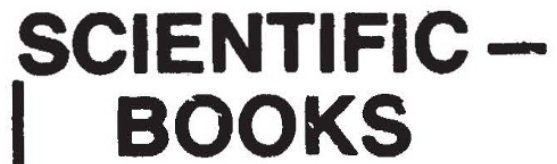

H. K. LEWIS can supply works in all branches of Pure and Applied Science. Catalogues on request. Please state interests.

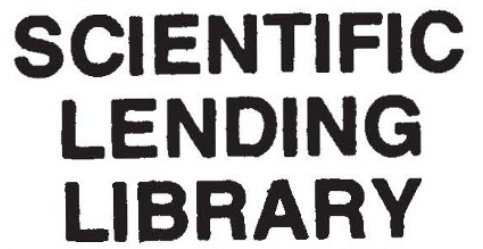

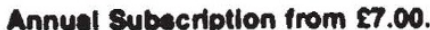
(Avaitable in U.K. only)

Reduced rates for multiple subscriptions.

Prospectus post free on request.

Quarterly List of New Books and now editions added to the Library sent post free to subscribers regularly.

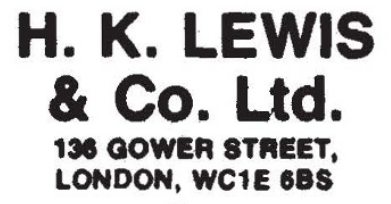

Telophono: 01.397 4202 Telograme: "Publicavh, condon, wcie ess."

Circle No. 10 on Reader Enquiry Card. 